\title{
EI IMPERATIVO DE LA AGRICULTURA HOY: CUIDAR LA TIERRA
}

\author{
Isaías Tobasura Acuña ${ }^{1}$. \\ Franco H. Obando Moncayo ${ }^{2}$
}

Recibido 15 de enero de 2014, aprobado el 9 de febrero de 2015 y actualizado el 09 de mayo de 2015

DOI:

10.17151/luaz.2015.41.21

\section{RESUMEN}

Desde que los humanos adquirieron conciencia de sus actos han generado relaciones de diverso orden con la tierra y sus habitantes. Con la emergencia de la agricultura, la tierra, de ser un bien libre y disponible para todas las criaturas vivientes, pasó a ser apropiado por los seres humanos para satisfacer necesidades. La tierra adquirió un valor utilitario, para producir alimentos y materias primas, y generar renta y poder político. No obstante, para los campesinos y pueblos indígenas, la tierra, además ha tenido y aún tiene un valor afectivo y sagrado. En esta lógica, la agricultura se constituye en vínculo de los seres humanos con la tierra, que conlleva un imperativo ético: cuidar la tierra, en tanto que esta es uno más de los sujetos de la comunidad ética. En este orden de ideas, este artículo discute el cuidado de la tierra como imperativo ético de la agricultura. Para ello, se analizan y discuten visiones de preservacionistas con visiones técnico-científicas de conservación de suelos.

\section{PALABRAS CLAVE}

Cuidado de la tierra, agricultura de conservación, conservación de suelos, ética de la tierra.

\section{THE IMPERATIVE OF AGRICULTURE TODAY: LAND CARE}

\begin{abstract}
Since humans became conscious of their actions they have generated relationships of various kinds with land and its inhabitants. With the emergence of agriculture the land, being a free good available for all living creatures, became appropiated by humans to satisfy their needs. The land acquired a utilitarian value to produce food and raw materials, and generate income and political power. However, for farmers and indigenous people land also has had and it still has an affective and sacred value. In this logic, agriculture constitutes a bond of human beings with the land, which embraces an ethical imperative: land care while it is just one other subject of the ethical community. In this order of ideas, this article discusses land care as an ethical imperative of agriculture. To do this, visions of preservationists with technicalscientific views of soil conservation are analyzed and discussed.
\end{abstract}




\section{KEY WORDS}

Land care, conservation agriculture, soil conservation, land ethics.

"La ética de la tierra [...] extiende las fronteras de la comunidad [moral]

para incluir los suelos, las plantas, los animales; dicho de un modo colectivo, la tierra"

(Aldo Leopold, 2000: 135)

"La agricultura debe ser [...] una de las pocas actividades que sirven para armonizar al ser humano con la naturaleza [para cuidar la tierra]" (Antonio Bello, 2002: 38)

\section{INTRODUCCIÓN}

La tierra es el soporte de todas las formas de vida y base del desarrollo de las sociedades humanas. En su conjunto, la tierra útil para dichos propósitos es un espacio finito y compartido con otras especies. Con el crecimiento de la población humana y la urbanización, la tierra pasó de ser un bien común de acceso libre a convertirse en un recurso limitado y un bien económico escaso. Hoy, la sociedad no solo está abocada a utilizar y compartir la misma tierra sino también a afrontar la degradación de esta por la actividad humana y por la propia dinámica de la naturaleza.

La población humana sigue creciendo y la demanda de alimentos y otros bienes y servicios para su sustento y bienestar aumentan, entre tanto los desiertos, eriales y tierras degradadas avanzan en el planeta. Perdurar en un mundo habitable, implica un compromiso y una responsabilidad ética de todos los habitantes del planeta: cuidar la tierra. El imperativo ético de la agricultura hoy es cuidar la tierra. Cuidarla no solo por un interés utilitario, productivo y económico, sino porque esta hace parte de nuestra comunidad moral. La naturaleza en general y la tierra en particular son nuevos objetos morales sobre los cuales la ética tiene que reflexionar.

Parodiando a Jonas (2004), nos preguntamos: ¿tiene la tierra un derecho moral propio? O, de otra manera: ¿tienen los humanos una responsabilidad ética con la tierra? No hay duda. La comunidad moral se ha extendido hasta incluir el planeta y todas las formas de vida que en él habitan. Él ha sido sometido a nuestro poder $y$ por ello se ha convertido en un bien encomendado a nuestro cuidado, y puede exigirnos un deber moral, no en razón de nuestro propio interés, sino en razón de él mismo y de su derecho propio. Eso implica no solo la búsqueda del bien humano, sino además el bien de las cosas extrahumanas; es decir, incorporar en el concepto de bien humano, el cuidado de la tierra y de sus huéspedes. 
En esta línea de ideas, y siguiendo a Serres (1991), implica un retorno a la naturaleza, de la que nunca debimos separarnos. Según los libros sagrados, hemos venido de la tierra y a ella hemos de volver: "polvo eres y en polvo te has de convertir" (Génesis, 3:19). El regreso a la naturaleza implica ampliar el contrato social de la modernidad a un contrato natural, un contrato de simbiosis y reciprocidad, basado en la escucha, la contemplación, la admiración, el cultivo y el afecto. "El simbionte admite el derecho del anfitrión, mientras que el parásito -nuestro estatuto actual- condena a muerte a aquel que saquea y que habita sin tomar conciencia de que en un plazo determinado él mismo está condenado a desaparecer" (Serres, 1991: 69).

La responsabilidad ética con el cuidado de la tierra como suelo cultivable, no es un asunto técnico propio de los agricultores, de los ingenieros agrónomos y de los científicos del suelo. El cuidado de la tierra, en este contexto, ha dado origen a la conservación del suelo como objeto de investigación por la comunidad científica. No hay duda de que en esta línea se ha avanzado, pero aún falta mucho por hacer, sobre todo en la concepción y enfoque de la conservación como una consecuencia del uso y manejo; en otras palabras, la conservación del suelo ha carecido de una reflexión ética sobre lo que involucra el cuidado de la tierra. Hablamos de cuidado de la tierra, mas no de conservación de suelos, porque "cuidar", significa proteger, proveer, dar afecto, mimar. Un concepto más apropiado con lo que significa está nueva responsabilidad moral de la comunidad humana.

Al igual que en la medicina, la conservación de los suelos se ha orientado a la recuperación y restauración de los suelos degradados, o literalmente lisiados. En nuestro concepto, el cuidado del suelo debe ser preventivo, igual que debería ser en la salud humana. No conocemos una teoría del cuidado de la tierra, pero sí avances teóricos y, sobre todo, técnicas para el control de la erosión y sedimentación y la restauración de suelos. Por ello, en este texto, se plantea el debate entre los conceptos "cuidado de la tierra" y "conservación del suelo". Se parte de que el primero -el cuidado- implica una responsabilidad, un imperativo ético con la tierra como un fin en sí mismo, en tanto que el segundo -la conservación- es una propuesta técnicoinstrumental en donde esta es un recurso, un medio para los fines humanos. En la primera parte, se presenta el enfoque técnico instrumental de la conservación de los suelos, en la segunda los fundamentos éticos del cuidado de la tierra $y$, finalmente, se termina con las ideas para un nuevo contrato de convivencia armónica con la tierra.

\section{CONSERVACIÓN DEL SUELO}

El planeta Tierra y su envoltura vital, la biosfera, es una maraña intrincada de elementos y relaciones, estrechas y permanentes, en las cuales todos los componentes y seres que la habitan están íntimamente ligados. La emergencia de la vida y la 
organización de la comunidad biótica y abiótica es producto de dicha complejidad de relaciones. Los males que hoy afectan la salud del planeta son diversos pero se acentúan con el crecimiento de la población y, sobre todo, con el estilo de desarrollo que esta ha adoptado. En esta concepción, el hombre se comporta como "un forastero que llega en la noche y extrae de la tierra aquello que necesita. La tierra no es su hermana sino su enemiga, y cuando ya la conquistó, prosigue su camino" (Carta del Jefe Seattle al presidente de los Estados Unidos, 1855).

La degradación de los suelos es en parte el resultado de dicho proceso, es decir, de pensar y utilizar el suelo solo con fines e intereses económicos utilitaristas. La agricultura y, específicamente, la agricultura industrializada es extractiva y agresiva con la tierra y otras formas de vida. Aunque las prácticas para remediar o enmendar el deterioro de los suelos son muy antiguas, la corriente de la conservación del suelo, por su valor utilitario es reciente (Riechmann, 2000). Y en esta misma lógica, los sistemas de conservación basados en el interés económico, producen desequilibrios irremediables, pues tienden a ignorar y a eliminar a muchos elementos de la comunidad de la tierra carentes de valor comercial, pero esenciales para su funcionamiento saludable. Se han eliminado selvas y cambiado el curso de los ríos, y valles y sabanas fértiles se han convertido en monumentos de cemento.

Según Miller (1990), la conservación del suelo es un proceso dirigido a la búsqueda de opciones de desarrollo de la calidad de vida humana, en términos de seguridad alimentaria, ingresos, salud y paz. Busca mantener la diversidad biológica, los recursos genéticos, y los procesos ecológicos, económicos e hidrológicos del suelo entre otros aspectos relevantes y vitales para la humanidad. Es, como hemos sostenido, una concepción antropocéntrica, orientada por los intereses humanos. $Y$ en esa concepción, el desarrollo es la transformación de la biosfera y el uso de los recursos naturales, humanos y financieros para satisfacer las necesidades humanas y mejorar su bienestar. Así, la conservación y el desarrollo, están dirigidos esencialmente al bienestar humano, es decir al logro de metas humanas. Y la conservación se dirige a alcanzar dichas metas, al asegurar que el uso y aprovechamiento de los recursos no se agoten ni deterioren, para satisfacer las necesidades de las generaciones presentes y futuras. Por lo tanto, la conservación es una consecuencia previsible de la utilización y manejo racional de los recursos naturales para los fines productivos humanos (Benites, 1996).

Los programas y proyectos de conservación del suelo alrededor del mundo no han tenido el éxito esperado debido a esa visión productivista de desarrollo, que domina los discursos y las prácticas de los investigadores de la ciencia del suelo. Muchos esfuerzos de investigación se han orientado a medir las pérdidas de suelo y al entendimiento del proceso físico de la erosión (Shaxson, 1994). Pero hubo y aún persiste una escasa preocupación respecto de la cantidad y calidad de suelo que permanece en el sitio, el cual tiene relevancia inmediata para la 
microfauna, el crecimiento de las raíces, la producción de cultivos y por ende para los agricultores. La asistencia técnica y la extensión rural se han concentrado en el tratamiento de las consecuencias de la erosión por medio de la construcción de obras físicas, las cuales parecían técnicamente adecuadas y estéticamente placenteras. Estas obras y desarrollos, además de estar orientados a restauración y remediación de daños, no han considerado el conocimiento ancestral ni las preocupaciones e intereses de los campesinos. En otras palabras, los saberes que los agricultores tienen sobre sus tierras no se consideran pieza importante de los proyectos de conservación del suelo; los agricultores no se han tenido en cuenta como parte de la solución, sino como causantes del problema de la degradación de las tierras. La visión ética de cuidado de la tierra sugiere que la solución al problema de degradación del suelo no es la "conservación del suelo" en el sitio, como se ha concebido desde la corriente técnico-instrumental conservacionista de la ciencia del suelo, sino el "cuidado de la tierra", que hacen los labriegos en sus sistemas de agricultura tradicionales, a lo cual se pueden añadir (si es necesario) técnicas apropiadas de manejo de suelos y obras de ingeniería o de bioingeniería.

En este sentido, la disciplina de conservación del suelo se ha venido apoyando en los principios de funcionalidad ecosistémica y resiliencia del suelo. Estos principios enfatizan en que el suelo es un cuerpo viviente, que ejerce funciones ecológicas esenciales para sostener la calidad de vida en el planeta (Dumanski et al., 2006). Y reconocen la importancia de los $20 \mathrm{~cm}$ superiores del suelo como la zona más activa, pero la zona más vulnerable a la erosión y degradación. La mayoría de las funciones y servicios ambientales esenciales para sostener la vida terrestre en el planeta están concentrados en la micro, meso y macrofauna y flora los cuales viven e interactúan en esta zona. Es estos principios se fundamenta la agricultura de conservación.

Según Dumanski et al. (2006), los criterios conexos que distinguen la agricultura de conservación de un sistema de agricultura convencional son: i) cobertura permanente del suelo; ii) mínimo disturbio mecánico del suelo; iii) selección atinada de rotación de cultivos; iv) localización precisa de insumos para reducir costos, optimizar eficiencia de operaciones y prevenir daños ambientales; v) promoción de barbechos de leguminosas (incluyendo herbáceas y arbóreas donde sean apropiadas), compostaje y el uso de abonos y otras enmiendas orgánicas para mejorar la estructura del suelo y la biodiversidad, y reducir la necesidad de fertilizantes inorgánicos; vi) promoción de la agroforestería (árboles en las fincas) para la obtención de fibras, frutas y productos medicinales. La agroforestería además se usa para control de erosión (árboles como barreras vivas en contorno), la conservación de la biodiversidad y, a través del proceso de fotosíntesis, la construcción de suelo y captura de carbono atmosférico por las plantas (Blum, 2010)

La cobertura permanente del suelo ya sea con plantas vivas (cultivos y arvenses de cobertura) o residuos de cosecha y arvenses, protege el suelo contra el impacto físico de la lluvia y el viento y regula la humedad y la temperatura en los estratos 
superficiales del suelo. Los residuos orgánicos contribuyen a mantener o aumentar la actividad de diversos organismos del suelo desde las lombrices de tierra y grandes insectos hasta hongos y bacterias (macro, meso y microorganismos) $y$, en consecuencia, a mantener los niveles y actividad de los materiales orgánicos con relación a sus múltiples efectos en las características físicas, químicas y biológicas, e hidrológicas de los suelos, incluyendo mayor ciclaje de nutrientes, reestructuración de los agregados del suelo, y los espacios entre los agregados, donde las raíces crecen, el agua se mueve, y los gases son intercambiados (Shaxson y Barber, 2003; Blank, 2008).

Un aspecto clave de los sistemas de agricultura de conservación, particularmente para las zonas tropicales de ladera, es que procuran simular las condiciones del bosque natural. Por lo tanto, incrementan las posibilidades de diversificación $y$, en consecuencia, mayor calidad y resiliencia del suelo (Brookfield y Stocking, 1999; Shaxson, 1994).

En síntesis, los sistemas de agricultura de conservación satisfacen sincrónicamente las preocupaciones de los agricultores de reducir costos de producción y obtener altos niveles de rendimiento de los cultivos, y los intereses de los científicos de mantener la estructura funcional del suelo. Por lo tanto, la agricultura de conservación es una de las estrategias clave para el mantenimiento de la calidad del suelo, entendida en el contexto de la agricultura sostenible como la capacidad para ejercer funciones agronómicas y ambientales. La agricultura sostenible, por su parte, encaja en un concepto más amplio que es el concepto de "desarrollo sostenible", que es aquel «desarrollo que satisface las necesidades de la generación presente sin comprometer la capacidad de las generaciones futuras para satisfacer sus propias necesidades» (CMMAD, 1988: 67). Y esto ratifica el fin utilitario que subyace al concepto de conservación de suelos.

\section{EL CUIDADO DE LA TIERRA}

La tierra se presenta como un libro abierto, el cual encierra en sus páginas los secretos que son necesarios conocer para tener una convivencia armónica con ella. Los campesinos, indígenas y afros saben mucho sobre sus tierras. Saben, como los agrónomos latinos, que tierras que no son para pan, sirven para pastos, para arboledas y otras cosas (Columella, 1998). Han aprendido de la convivencia con la tierra, de descifrar sus secretos, que su aprovechamiento depende de su naturaleza, de su vocación natural. Se han dado cuenta de que con el paso del tiempo y la explotación intensiva la tierra se agota, se cansa y pierde sus condiciones innatas de producción. También saben que las tierras no deben exponerse al abandono, sino que ellas requieren dedicación y cuidado, que se les debe querer como a una madre. 
No obstante, entre los científicos de la ciencia del suelo, el "cuidado de la tierra" es un concepto relativamente nuevo. Roose (1996) y Shaxson y Douglas (2004) lo han presentado como uno de los enfoques de "conservación de suelos", en el sentido amplio que se aplica al cultivo de plantas y cría de animales. Así: "as concept signifying active care for their well being, it is equally applicable to land. Según Shaxson y Douglas (2004: 977):

"Animal husbandry, crop husbandry, and land husbandry have, in common, the need for the farmer/land-user to:

a) understand the characteristics of different types of plants, animals, and lands; b) predict their likely responses to changes in management and to severe environmental events;

c) devise means of strengthening them against damage;

d) maintain their productivity and usefulness for the chosen purposes".

En este texto, el "cuidado de la tierra", incorpora la dimensión ética en la relación que los seres humanos establecen con la tierra. Se sustenta en el hecho de que ella hace parte de nuestra comunidad moral, que es junto con los animales, las plantas y los humanos, uno más dentro de los sujetos y objetos morales. En palabras de Leopold (2000, p. 135): "La ética de la tierra [...] extiende las fronteras de la comunidad [moral] para incluir los suelos, las plantas, los animales; dicho de un modo colectivo, la tierra". Y eso mismo, lo había dicho el Jefe Seattle al presidente de Estados Unidos en su célebre carta de 1855, en la cual se puede apreciar la manera como los aborígenes se relacionaban con la tierra y con los demás miembros de la comunidad biótica:

Cada pedazo de esta tierra es sagrado para mi pueblo. Cada rama brillante de un pino, cada puñado de arena de las playas, la penumbra de la densa selva, cada rayo de luz y el zumbar de los insectos son sagrados en la memoria y vida de mi pueblo. [...] Los muertos del hombre blanco olvidan su tierra de origen cuando van a caminar entre las estrellas. Nuestros muertos jamás se olvidan de esta bella tierra, pues ella es la madre del hombre piel roja. Somos parte de la tierra y ella es parte de nosotros. Las flores perfumadas son nuestras hermanas; el ciervo, el caballo, el gran águila, son nuestros hermanos. Los picos rocosos, los surcos húmedos de las campiñas, el calor del cuerpo del potro y el hombre, todos pertenecen a la misma familia.

También científicos del suelo, como Hans Jenny, consideran que el suelo, además de las funciones ecosistémicas y productivas, tiene funciones estéticas, que despiertan emociones y sirven de 
inspiración a trabajadores del arte: pintores, fotógrafos, escritores y a la gente común. Veamos:

[...] soils appeals to my senses. I like to dig in it and work it with my hands. I enjoy doing the soil texture feel test with my fingers or kneading a clay soil, which is a short step from ceramics or sculptures. Soil has a pleasant smell. I like to sit on bare, sun-drenched ground and take in the fragrance of soil. As yet, neither touch nor smell sensations have been accorded aesthetic recognition, but colors delight painters, photographers, and writers, as well as you and me. [...] Whenever I offer this reaction to an audience, I notice smiles and curiosity, but when I follow up with slides that depict ebony black mollisols of Canada, titian red oxisols of Hawaii, and gorgeous soil profile paintings by such famous artists as Grant Wood of lowa, Dubuffet of France and Schmidt- Rottluff of Germany, they hesitancy turns into applause. (Jenny, 1984: 158)

En los términos que hemos venido debatiendo, hace parte de la misma comunidad moral. Pero ¿por qué debemos cuidar la tierra? ¿Acaso como se ha entendido en la tradición antropocéntrica, por un interés utilitario, porque de ella derivamos nuestros alimentos y otros bienes? El razonamiento de los que así piensan se deriva de proverbios según los cuales no debemos matar la gallina de los huevos de oro, ni tampoco debemos cortar la rama de la cual estamos colgados. Así es en la ética antropocéntrica, donde el hombre no solo es el dueño sino también el dominador de la tierra. En este caso, cuidar la tierra es un imperativo hipotético, tal como: si quiero tierra productiva para las futuras generaciones, debo cuidar la tierra. En la otra concepción, en la biocéntrica, la tierra se debe cuidar por consideraciones morales más allá de los intereses utilitarios, por el valor intrínseco que ella posee, como un imperativo ético categórico, es decir en todos los casos. Se debe preservar porque ella hace parte de la comunidad moral y, por tanto, se le debe usar y proteger de acuerdo con sus condiciones naturales. Esta concepción sostiene que $A$ debe algo positivo a $B$ no en virtud de ninguna relación causal de A con $B$ o cualquier acuerdo previo establecido, sino simplemente porque $A$ es capaz de beneficiar a B o aliviar su sufrimiento. No se trata de obligaciones y deberes de ciudadanía como pregonan los defensores de la "ciudadanía ecológica" (Dobson, 2010).

La anterior concepción no es fácil de asimilar y entender. "A excepción de la religión, ninguna ética anterior nos ha preparado para el papel de fiduciarios; y menos aún nos ha preparado para ello la visión científica hoy dominante de la naturaleza" (Jonas, 2004: 35). La visión de desarrollo dominante, sobre la cual cabalga la agricultura moderna industrializada, se sustenta en la racionalidad instrumental con arreglo a fines y en la ciencia occidental como manera hegemónica de conocer y transformar la naturaleza, la cual ha reducido la tierra como suelo cultivable a medio o recurso para los fines del hombre. No obstante, y tal vez, 
no por razones altruistas sino egoístas, hoy surgen corrientes de pensamiento que abogan por una nueva relación con el planeta y sus diferentes formas de vida, entre ellas la tierra.

El modelo de sociedad actual nos ha llevado a asumir posturas distantes de la naturaleza. Los humanos se han escindido de la naturaleza, no se consideran parte de ella. Muchos, incluso, han perdido la noción de dónde llegan el agua y los alimentos que consumimos a diario en las ciudades. Los más por estar aglomerados en las grandes urbes y, los menos, pero los más voraces, porque lo único que ven en ella es una fuente de riqueza que hay que extraer a como dé lugar. Así:

Al igual que nos volvemos a la naturaleza, nos alejamos de Dios. No entendemos las notas de los pájaros. El zorro y el ciervo huyen de nosotros; el oso y el tigre nos desgarran. Solo conocemos la utilidad de unas cuantas plantas, como el trigo, la manzana, la papa y la vid. ¿Acaso no vislumbramos cada vez que miramos el paisaje una grandeza, un rostro suyo? (Emerson, 2000: 73)

Cuidar la tierra implica cambiar la relación que tenemos con ella, empezando por la forma como la apreciamos y valoramos. Hay que dejar que los sentidos se impresionen frente a su majestuosidad. Quien no ha experimentado el olor fresco del suelo en el bosque, no sabe de su aroma embriagante que exhala. Quien no ha caminado descalzo sobre la tierra recién arada no ha experimentado la conexión con sus entrañas. Contemplar con atención el movimiento de las partículas heridas por la reja del arado, genera imágenes contradictorias, de dolor por las heridas abiertas y de emoción por la vida que se descubre a nuestros ojos. Cambiar la relación con la tierra, implica volver a ella; hacer parte de su ser.

\section{CONSIDERACIONES FINALES. HACIA UN CONTRATO NATURAL.}

El imperativo moral de hoy es establecer un nuevo contrato con la tierra, un contrato social extendido con la comunidad moral ampliada, como diría Serres (1991), "un contrato natural". Hemos esbozado algunas razones para establecer dicho compromiso. No obstante, en esta parte esgrimimos una que nos parece crucial en estos tiempos. Ella deriva del poder que, por medio de la técnica, ha conquistado el hombre moderno. Así:

La techne, en su forma de técnica moderna, se ha transformado en un infinito impulso hacia adelante de la especie, en su impulso, en su empresa más importante, en cuyo continuo progresar que se supera a sí mismo hacia cosas cada vez más grandes se intenta ver la misión de la humanidad, y cuyo éxito en lograr el máximo 
dominio sobre las cosas y los propios hombres se presenta como la realización de su destino. (Jonas, 2004: 36)

O como anota Heidegger (2003: 123), en el texto "La pregunta por la técnica", acerca de la técnica moderna: es igual que la técnica antigua, pero el des-ocultar no se despliega en producir, "El des-ocultar en la técnica moderna es un provocar que pone a la naturaleza en la exigencia de liberar energías, que en cuanto tales pueden ser explotadas o acumuladas". Y eso es, ni más ni menos, lo que diferencia la agricultura tradicional de la agricultura moderna. Veamos:

[...] el campo, que el campesino antiguamente labraba, en donde labrar aún quiere decir: cuidar y cultivar [está en decadencia]. El hacer del campesino no provoca al campo. En el sembrar las simientes, abandona él la siembra a las fuerzas del crecimiento y cuida su germinación. Entre tanto, la labranza del campo [hoy] ha caído en la resaca de otro modo de labrar, que pone a la naturaleza. La pone en el sentido de provocación. El campo es ahora industria motorizada de alimentación [al servicio del capital]. (Heidegger, 2003: 123)

Para el campesino la tierra no es un medio, un recurso para la producción y nada más; la tierra es hasta cierto punto el origen, "la madre"; la tierra hace parte de su ser, de su identidad; el campesino ama la tierra y por eso la cuida, y llora y se siente desamparado cuando la pierde. El campesino pone la semilla en el surco, usando solo la energía de sus propias manos para que cobre vida, sin exigirla; mientras el empresario planta la semilla mecánicamente, y utilizando energía proveniente de combustibles fósiles; fuerza la tierra, con insumos ajenos a su naturaleza para que produzca más y más. En esta lógica de producción está buena parte de los orígenes de los problemas ambientales de la producción agrícola moderna, y entre ellos, el deterioro de los suelos.

Con el desarrollo científico-técnico el poder causal del hombre como sujeto moral se ha incrementado de forma dramática. Las fantasías del hombre de antaño por llegar al fondo de la tierra, alcanzar las encumbradas cimas, llegar a recónditos lugares y conquistar el espacio y visitar otros planetas, han dejado de ser una ficción para ser una realidad. Ese nuevo poder del hombre como sujeto moral, le exige una mayor responsabilidad. Y en el caso particular, de la relación que establece con la tierra, en la agricultura, le exige un compromiso ético: cuidar la tierra.

Este imperativo ético se sustenta en el hecho de que la agricultura es un medio que nos permite estrechar los vínculos con la tierra. Esa es la agricultura de los pueblos tradicionales: cultivar plantas y criar animales. Dos expresiones del cuidado que los labriegos prodigan a quien le da alimento para saciar el hambre, pieles y lana para soportar los fríos y maderas y fibras 
para protegerse. A través del tiempo, los labradores han aprendido que el soporte en el que se gestan las simientes -el suelo o la tierra- requiere unas condiciones de cuidado sin las cuales las funciones vitales para prodigar la vida se resienten. Por eso lo alimentan con residuos, le devuelven los estiércoles de sus animales, le dan abrigo con sus árboles y lo protegen de los vientos, lo abrazan con su mirada y lo acarician con sus pies. Y en esas prácticas cotidianas el campesino expresa su compromiso ético con la tierra: la cuidan como a su propia madre.

\section{REFERENCIAS}

- Bello, A. (2002). Agricultura, simplemente Agricultura. En: Cuidar la T(tierra). Jorge Riechmann (2003). España (Icaria).

- Benites, R. J. (1996). Erosion-induced loss in soil productivity: causes and solutions. Second workshop held at the Centre for Research on small farmers, Brazil.

- Blank, D. (2008). A Fresh look at life below the surface. In: T.G. Goddard, Zoebisch, M., Gan, Y., ellis, W., Watson, A. Sombatpanit, S. 2008. No-till farming systems. World Association of Soil and Water Conservation, Special Bulletin No. 3. Bangkok, Thailand.

- Blum, W. (2010). Driving forces of soil formation - A global approach.16o Congreso de la Organización Internacional de conservación de Suelo, ISCO-2010. Proceeding contribution in extenso. Santiago de Chile 08-12 de noviembre de 2010. 529 p: 508-511.

- BrookfieldL, H. Stocking, M. (1999). Agrodiversity: definition, description and design. Global Environmental Change 9 (2): 7780.

- Carta del Jefe Seattle al presidente de los Estados Unidos. (1855). Recuperado de http://www.ciudadseva.com/textos/otros/carta_del_jefe seattle_al_presidente_de_los_estados_unidos.htm

- Columella, M. (1998). De los trabajos del campo. España: Siglo XXI.

- Comisión Mundial de Medio Ambiente y Desarrollo (1988): Informe Nuestro Futuro Común, Alianza Editorial, Madrid.

- Dobson, A. (2010). Ciudadanía y medio ambiente. España: Editorial Proteus.

- Dumanski, J. et. Al. 2006. The paradigm of conservation agriculture. Proceeding World Association of Soil and Water Conservation, p: 58-64.

- Emerson, R. W. (2000). Naturaleza. Bogotá: Editorial Norma.

- Heidegger, M. (2003). Filosofía, ciencia y técnica. Santiago de Chile: Ed. Universitaria.

- Jenny, H. (1984). My friend, the soil. Journal of Soil and Water Conservation, 39(3), 158-161.

- Jonas, H. (2004). El principio de responsabilidad. Ensayo de una ética para la civilización tecnológica. España: Ed. Herder.

- Leopold, A. (2000). Una ética de la tierra. Madrid: Ed. La Catarata. 
- Miller, K. R. (1990). Hacia la sostenibilidad de la conservación y el desarrollo. En Memorias del simposio internacional de Ecobios Colombia 88. El desarrollo sostenible; estrategias, políticas y acciones. Bogotá.

- Riechmann, J. (2000). Introducción: Aldo Leopold, los orígenes del ecologismo estadounidense y la ética de la Tierra. En Una ética de la tierra. Madrid: La Catarata.

- Roose, E. (1996). Land husbandry. Components and strategy. Roma: FAO.

- Serres, M. (1991). El contrato natural. España: Ed. Pre-textos.

- Shaxson, T. F. (1994). Introducción al concepto moderno de manejo integrado y conservación de suelos. En Memorias del taller sobre planificación participativa de conservación de suelos y aguas. FAO. Proyecto Regional GCP/RLA/107/JON, Chile.

- Shaxson, T.F. and Barber, R. (2003). Optimizing soil moisture for plant production. Soils Bulletin 79, Food and Agriculture Organization of the United Nations, Rome, Italy.

- Shaxson, F. y Douglas M. (2004). Land husbandry. En Lal, R. (Ed.). Encyclopedia Soil Science (pp. 971-977). Second Edition. Vo II. CRC Press.

1. Doctor Sociología del medio ambiente. Profesor Universidad de Caldas, Manizales, Colombia. E-mail: isaias.tobasura@ucaldas.edu.co

2. PhD. Suelos. Profesor Universidad de Caldas. E-mail: francoh.obando@ucaldas.edu.co

Para citar este artículo: Tobasura Acuña, I. y Obando Moncayo, F. H. 2015). El imperativo de la agricultura hoy: cuidar la tierra. Revista Luna Azul, 41, 385-396. Recuperado de http://lunazul.ucaldas.edu.co/index.php?option=content\&tas k=view\&id=1072 